\title{
Molecular profiling of Chinese systemic anaplastic large cell lymphoma patients: novel evidence of genetic heterogeneity
}

\author{
Li-Hua Zhong ${ }^{1}$, Zhi-Da Wu ${ }^{1}$, Jian-Chao Wang ${ }^{1}$, Zai-Zeng Wu ${ }^{1}$, Fang-Fang Chen ${ }^{1}$, Wei-Feng Zhu ${ }^{1}$, \\ Yan-Ping Chen ${ }^{1}$, Gang Chen ${ }^{1,2}$ \\ ${ }^{1}$ Department of Pathology, Fujian Medical University Cancer Hospital and Fujian Cancer Hospital, Fuzhou, China; ${ }^{2}$ Fujian Provincial Key \\ Laboratory of Translational Cancer Medicine, Fuzhou, China \\ Contributions: (I) Conception and design: LH Zhong, G Chen; (II) Administrative support: LH Zhong, G Chen; (III) Provision of study materials or \\ patients: All authors; (IV) Collection and assembly of data: All authors; (V) Data analysis and interpretation: All authors; (VI) Manuscript writing: All \\ authors; (VII) Final approval of manuscript: All authors. \\ Correspondence to: Gang Chen. Department of Pathology, Fujian Medical University Cancer Hospital and Fujian Cancer Hospital, Fuzhou 350014, \\ China. Email: naichengang@fjmu.edu.cn.
}

Background: Anaplastic large cell lymphoma (ALCL) is a rare non-Hodgkin lymphoma. A comprehensive understanding of the genetic and clinical heterogeneity of ALCL may help to improve the clinical management of patients with ALCL. However, due to the rarity of the disease, the genetic heterogeneity of ALCL has not been well elucidated. This study aimed to comprehensively elucidate the mutational landscape of tumor tissue samples from patients with systemic ALCL.

Methods: Thirty-six patients with systemic ALCL were enrolled in this retrospective study. Immunohistochemistry (IHC) was performed on tumor tissues at baseline to identify anaplastic lymphoma kinase $(A L K)$ fusions. Capture-based targeted next-generation sequencing (NGS) with a panel spanning 112 lymphoma-related genes, including $A L K$ rearrangements, was also performed on tumor tissue samples.

Results: A total of 102 mutations were identified in the entire cohort. Among the 36 patients included in this analysis, 14 (38.8\%) were $A L K$ positive, as determined by IHC, while NGS showed 12 patients $(33.3 \%)$ to harbor $A L K$ rearrangements. Younger patients were more likely to have $A L K$-positive ALCL (P=0.011). Patients with wild-type (WT) $A L K$ were more likely to have single-nucleotide variants (SNVs) and insertions or deletions (INDELs) than patients with $A L K$ rearrangements $(\mathrm{P}=0.027)$. Among the 22 patients with WT ALK, the most commonly mutated genes were TP53 (n=6, 27.3\%), followed by NOTCH1 (n=5, 22.7\%), KMT2D (n=3, 13.6\%), KRAS (n=3, 13.6\%), TET2 (n=3,13.6\%), and FAK1 (n=2, 9.1\%). Mutations in PRDM1, a commonly mutated gene in $A L K$-negative patients, were not detected in our $A L K$-negative cohort. Start-loss of beta-2-microglobulin $(B 2 M)$ was detected in another patient; this patient had a favorable prognosis, with an overall survival exceeding 19 months.

Conclusions: Our study revealed the unique genomic profiles of Chinese ALCL patients and represents an incremental step in deepening the understanding of the genetic heterogeneity of ALCL patients.

Keywords: Systemic anaplastic large cell lymphoma (systemic ALCL); somatic mutation; genetic heterogeneity; novel $A L K$-fusion

Submitted Oct 10, 2020. Accepted for publication Dec 10, 2020.

doi: $10.21037 / \mathrm{atm}-20-7574$

View this article at: http://dx.doi.org/10.21037/atm-20-7574 


\section{Introduction}

Anaplastic large cell lymphoma (ALCL) refers to a group of CD30-positive T-cell non-Hodgkin lymphomas $(1,2)$. ALCL, which accounts for $13.8 \%$ of all peripheral T-cell lymphomas (PTCLs) (3), can be classified as primary cutaneous ALCL (pcALCL) and systemic ALCL. According to the World Health Organization (WHO) classification of Tumors of Hematopoietic and Lymphoid Tissues, systemic ALCL can be further divided based on anaplastic lymphoma kinase $(A L K)$ status as $A L K$-negative ALCL and $A L K$-positive ALCL, the identification of which depends on either immunohistochemistry (IHC) or fluorescence in situ hybridization (FISH) (1).

In recent years, gene rearrangement or overexpression of $A L K$ has been considered to be a favorable prognostic biomarker for ALCL patients (4,5). Approximately half of the patients diagnosed with ALCL have ALK-positive status and have high response to standard chemotherapy regimen consisting of cyclophosphamide, doxorubicin, vincristine, and prednisone or prednisolone (CHOP) (6). Contrastingly, due to inefficacy of standard regimens, patients with $A L K$-negative ALCL often undergo more intensive therapies than $A L K$-positive ALCL patients (7-9). A growing number of studies have reported that the 5-year survival of a subset of $A L K$-negative ALCL patients with dual specificity phosphatase 22 (DUSP22) rearrangement was comparable to that of $A L K$-positive ALCL patients who received the same treatment regimen (9-11). Routine stem cell transplantation may lead to overtreatment for subsets of $A L K$-negative ALCL patients, such as those with DUSP22 rearrangement, resulting in unnecessary increases in costs and risks for those patients. Rearrangements involving the tumor protein p63 (TP63) is considered to be a biomarker of poor prognosis for $A L K$-negative ALCL patients, with a 5 -year survival rate of only $17 \%$ (10).

The National Comprehensive Cancer Network (NCCN) Clinical Practice Guidelines in Oncology for T-Cell lymphomas recommend that molecular analysis is used to detect DUSP22 rearrangement if $A L K$-negative ALCL is diagnosed and follow the same recommended treatment regimen as that for $A L K$-positive patients (10-13). Illumination of the genetic and clinical heterogeneity of ALCL patients may facilitate improvements in the clinical management of ALCL patients. However, due to the rarity of ALCL, the genetic heterogeneity of this disease has not been well investigated. In this study, we retrospectively enrolled 36 systemic ALCL patients and performed genetic profiling of their tumor tissue samples using capture-based targeted next-generation sequencing (NGS) with a panel spanning 112 lymphoma-related genes, in order to elucidate the somatic profiles of ALCL patients with distinct clinical features. We present the following article in accordance with the MDAR reporting checklist (available at http:// dx.doi.org/10.21037/atm-20-7574).

\section{Methods}

\section{Patient and study design}

This retrospective study included 36 patients who were diagnosed with systemic ALCL according to the WHO classification of Tumors of Hematopoietic and Lymphoid Tissue (2008) between January, 2015 and July, 2018 in Fujian Medical University Cancer Hospital and Fujian Cancer Hospital. All procedures involving human participants were performed in accordance with the Declaration of Helsinki (as revised in 2013). The study protocol was approved by the Ethics Committee of Fujian Medical University Cancer Hospital and Fujian Cancer Hospital (approval number: 2017-055-01). Written informed consent was provided by all the patients included in the study.

Patient clinical data including age, sex, anatomic site, sites of extra nodal involvement, skin involvement during the disease course, disease stage, first-line treatment, treatment response, survival, and immunophenotype [CD3 antigen (CD3), Ki67 antigen (Ki67), BCL2 apoptosis regulator (BCL2), BCL6 transcription repressor (BCL6), or tumor necrosis factor (TNF) receptor superfamily member 8 (CD30)] were collected. Treatment response was assessed by the investigators according to the response evaluation criteria in lymphoma (RECIL) of the International Working Group (14). ALK status was detected by performing IHC. The threshold for immunopositivity was $\geq 20 \%$ of tumor cells (CD30 $\geq 80 \%$ ). FISH was performed to detect DUSP22 rearrangement. Capture-based targeted NGS with a panel spanning 112 lymphoma-related genes (Burning Rock Biotech, Cat. No. LK205) was performed on tissue samples collected at baseline. Overall survival (OS) was evaluated from the time of initial diagnosis to death, or last follow-up in surviving patients.

\section{DNA extraction and library preparation}

DNA was extracted from formalin-fixed paraffin-embedded 
(FFPE) tissue samples using a QIAamp DNA FFPE tissue kit (Qiagen, Hilden, Germany) according to the manufacturer's protocol. The DNA concentration was determined using the Qubit dsDNA assay (Life Technologies, Carlsbad, CA, USA). The M220 Focusedultrasonicator (Covaris, Woburn, MA, USA) was used for DNA fragmentation, which was followed by end repair, phosphorylation, and adaptor ligation. DNA fragments of 200 to 400 bp were selected with AMPure beads (Agencourt AMPure XP kit; Beckman Coulter, Brea, CA, USA), and hybridization with capture probe baits, hybrid selection with magnetic beads, and polymerase chain reaction amplification were subsequently performed. A highsensitivity DNA assay was used to examine the quality of the DNA (Bioanalyzer 2100; Agilent Technologies, Santa Clara, CA, USA). Indexed samples were sequenced using a Nextseq500 sequencer (Illumina, Inc., Hayward, CA, USA) with paired-end reads.

\section{Sequencing data analysis}

Sequencing data were mapped to the human genome (hg19) using Burrows-Wheeler aligner version 0.7.10 (15). Local alignment optimization, variant calling, and annotation were performed with GATK version 3.2 (Broad Institute, Cambridge, MA, USA) (16), and VarScan version 2.4.3 (Genome Institute, Washington University, Washington, DC, USA) (17). Loci with a depth of less than 100 were filtered out using the VarScan filter pipeline. At least five and eight supporting reads were required for insertions or deletions (INDELs) and single-number variations (SNVs), respectively. For all targeted regions, the aimed average sequencing depth was 2,000x. Variants with a population frequency $>0.1 \%$ in public databases, including Exome Aggregation Consortium, 1,000 Genomes Project, ESP6500SI-V2 and dbSNP, were categorized as singlenucleotide polymorphisms (SNPs) and were excluded from further analyses. The ANNOVAR (18) and SnpEff version 3.6 (Wayne State University, Detroit, MI, USA) (19) softwares was used to annotate the remaining variants. Factera version 1.4.3 was employed for DNA translocation analysis (20).

Copy number variation $(\mathrm{CNV})$ analysis was performed based on the depth of coverage data of capture intervals and corrected against sequencing bias resulting from GC content and probe design. The coverage of different samples was normalized to comparable scales based on the average coverage of all captured regions. The limits for $\mathrm{CNV}$ detection were 1.5 and 2.64 for deletions and amplifications, respectively.

\section{Statistical analysis}

All analyses were conducted in R, version 3.3.3 (http:// www.R-project.org) and SPSS 22.0 (SPSS Inc., Chicago, IL, USA). Fisher's exact tests and $t$-tests were performed. A two-sided $\mathrm{P}$ value of $\leq 0.05$ was considered to show a statistically significant difference.

\section{Results}

\section{Patient characteristics}

The cohort was comprised of $67 \%$ males and $33 \%$ females with a median age of 38.5 years. Of the 36 ALCL patients evaluated by IHC, 14 were $A L K$-positive and 22 were $A L K$-negative. In three of the $A L K$-negative patients, DUSP22 rearrangement was detected by FISH. Fifteen patients displayed extranodal involvement at diagnosis, and two patients had skin involvement during their disease course. Overall, $50 \%(\mathrm{n}=18)$ of patients received a $\mathrm{CHOP} /$ CHOP-like regimen as the first-line treatment. A 15-yearold patient and a 13-year-old patient received BFM90 and BFM95 regimens, respectively. One patient underwent radiotherapy. Five patients did not receive any treatment, and the remaining 10 patients had no treatment information available. The median follow-up time was 26 months and the median overall survival was 42 months (range, 1103 months). Demographic and clinical characteristics of the patients are shown in Table 1.

\section{The mutation landscape of the entire cohort}

Thirty-six patients with available baseline tumor tissue samples were included in the baseline mutation landscape analysis. A total of 102 mutations were identified from the entire cohort. The mutation landscape of the cohort is presented in Figure 1A. Mutations were detected in the tumor tissue samples of $81 \%(29 / 36)$ of patients. Twelve patients (33\%) had $A L K$ rearrangement, and one patient had an SNV of $A L K$. With IHC used as a reference, our capturebased targeted NGS had a sensitivity of $85.7 \%(12 / 14)$ and a specificity of $100 \%$ for identifying $A L K$ status in biopsy samples. Two patients with $A L K$ fusion detected by IHC were not identified by NGS. The tumor cell fraction in one of these samples was $<30 \%$, while the DNA from the other 


\section{Page 4 of 9}

Table 1 Characteristics of patients

\begin{tabular}{|c|c|}
\hline Characteristics & Num. (percentage) \\
\hline \multicolumn{2}{|l|}{ Age (year) } \\
\hline \multicolumn{2}{|l|}{ Median: 38.5 (3-81) } \\
\hline \multicolumn{2}{|l|}{ Gender } \\
\hline Female & $12(33.3)$ \\
\hline Male & $24(66.7)$ \\
\hline \multicolumn{2}{|l|}{ Ann Arbor stage } \\
\hline$I-I I$ & $7(19.4)$ \\
\hline III-IV & $10(27.7)$ \\
\hline Missing & $19(52.8)$ \\
\hline \multicolumn{2}{|c|}{ Extranodal involvement at diagnosis } \\
\hline Yes & $15(41.7)$ \\
\hline No & $2(5.6)$ \\
\hline Missing & $19(52.8)$ \\
\hline \multicolumn{2}{|c|}{ Skin involvement during disease course } \\
\hline Yes & $2(5.6)$ \\
\hline No & $8(22.2)$ \\
\hline Missing & $26(72.2)$ \\
\hline \multicolumn{2}{|l|}{ Initial treatment } \\
\hline CHOP/CHOP-like & $18(50.0)$ \\
\hline Others & $3(8.3)$ \\
\hline None & $5(13.9)$ \\
\hline Missing & $10(27.8)$ \\
\hline
\end{tabular}

CHOP, doxorubicin, cyclophosphamide, vincristine, prednisone.

sample was heavily degraded when NGS was performed. Among the 12 patients who had $A L K$ rearrangements revealed by NGS, nucleophosmin 1 (NPM1) was the most common gene fusion partner, which was harbored by $7(58 \%)$ patients. The other ALK gene fusion partners detected from the cohort included 5-aminoimidazole4-carboxamide ribonucleotide formyltransferase/IMP cyclohydrolase $(A T I C)-A L K(\mathrm{n}=2)$, trafficking from ER to Golgi regulator $(T F G)(\mathrm{n}=1)$, tropomyosin 3 (TPM3) $(\mathrm{n}=1)$, and myosin heavy chain 9 (MYH9) $(\mathrm{n}=1)$. Other commonly seen mutations included tumor protein p53 (TP53) (19.4\%) and lysine methyltransferase 2D (KMT2D) (11.1\%).

Compared with $A L K$-positive ALCLs, which have been well characterized at the molecular level, little is known about the genetic features of $A L K$-negative ALCLs. We
Zhong et al. Genetic profiles of Chinese systemic ALCL patients

compared the mutation landscape between patients with IHC-based $A L K$-negative and $A L K$-positive status. Patients with IHC-based $A L K$-negative status had significantly more SNVs and INDELs $(\mathrm{P}=0.027)$ (Figure $1 B$ ). Among the 22 IHC-based $A L K$-negative patients, the most common mutation was TP53 $(\mathrm{n}=6,27.3 \%)$, followed by notch receptor $1(N O T C H 1)(\mathrm{n}=5,22.7 \%), K M T 2 D(\mathrm{n}=3,13.6 \%)$, KRAS proto-oncogene, GTPase (KRAS) $(\mathrm{n}=3,13.6 \%)$, TET methylcytosine dioxygenase 2 (TET2) ( $\mathrm{n}=3,13.6 \%)$, Janus kinase 1 ( $(\mathcal{A} A K 1)(\mathrm{n}=2,9.1 \%)$, signal transducer and activator of transcription 3 (STAT3) $(\mathrm{n}=1,4.5 \%)$, and Fas cell surface death receptor $(F A S)(\mathrm{n}=1,4.5 \%)$. Of note, start-loss of beta-2-microglobulin $(B 2 M)$ was detected in a 53 -year-old $A L K$-negative patient (Figure 2) who was diagnosed with stage IIA ALCL with liver involvement at diagnosis and had no skin involvement during the disease course. This patient received a CHOP-like regimen as first-line treatment and achieved partial response, with progression-free survival and OS of 13 months and 93 months and counting, respectively. DUSP22-rearrangement, a favorable prognostic biomarker of $A L K$-negative ALCL, was detected in the same patient.

\section{The correlation between ALK fusion status and various clinical parameters}

The correlations between $A L K$ fusion status and various clinical parameters were further investigated. $A L K$-positive ALCL was observed to be more common among younger patients $(\mathrm{P}=0.011)$, and $A L K$-negative patients were more likely to be $\mathrm{CD} 3$ positive $(\mathrm{P}=0.03)$ (Figure 3$)$. No differences were observed between $A L K$ fusion and Ki67 $(\mathrm{P}=0.64)$, sex $(\mathrm{P}=1)$, BCL2 $(\mathrm{P}=0.13)$, BCL6 $(\mathrm{P}=0.14)$, or disease stage $(\mathrm{P}=0.75)$.

\section{Discussion}

In this study, we revealed the somatic genomic landscapes of systemic ALCLs in 36 Chinese patients. We found that younger patients were more likely to be $A L K$ positive, while patients with $A L K$ wild-type (WT) ALCLs were more likely to have SNVs and INDELs than patients with $A L K$ rearrangements. Overall, our study revealed new evidence of genetic heterogeneity between Chinese ALCL patients.

Due to the rarity of ALCL, the genetic and clinical heterogeneity of patients with the disease are not well understood. $A L K$-fusion is known to be more likely to occur in younger ALCL patients $(4,7)$. The majority of 
$\infty$
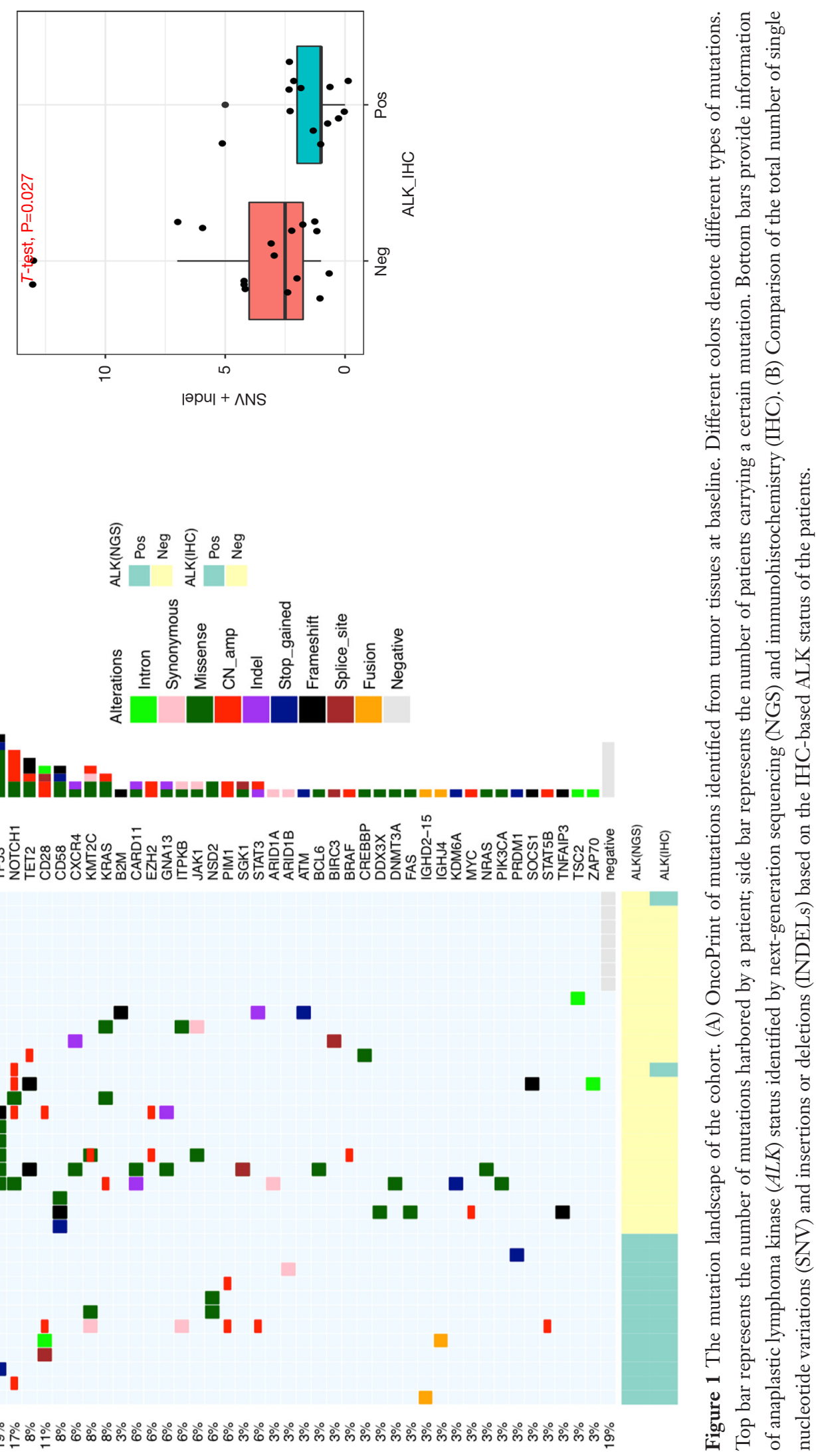

《 우 0 + N O 


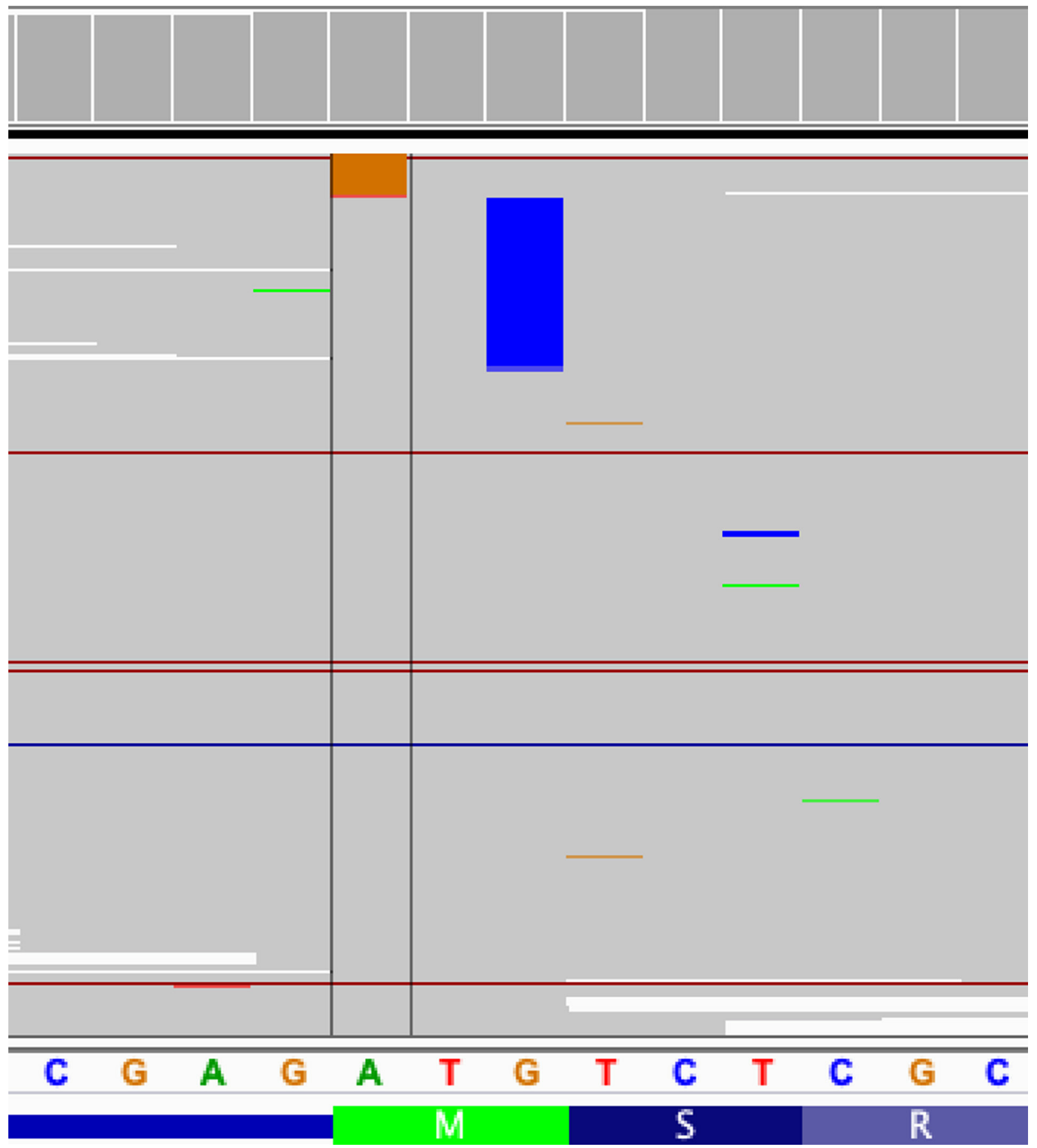

Figure 2 Allelic context of beta-2-microglobulin $(B 2 M)$ in one patient. Next-generation sequencing analysis revealed start-loss of $B 2 M$ (yellow and blue).

$A L K$-rearranged ALCLs have translocations involving the $A L K$ gene and its partner NPM1 (21). In the current cohort, the median age of the patients with $A L K$-positive ALCL was significantly younger than that of the $A L K$ - negative patients. NPM1-ALK was the most common $A L K$ rearrangement, which is consistent with the results of a previous study (21).

Compared with $A L K$-positive ALCLs, which are well 
A

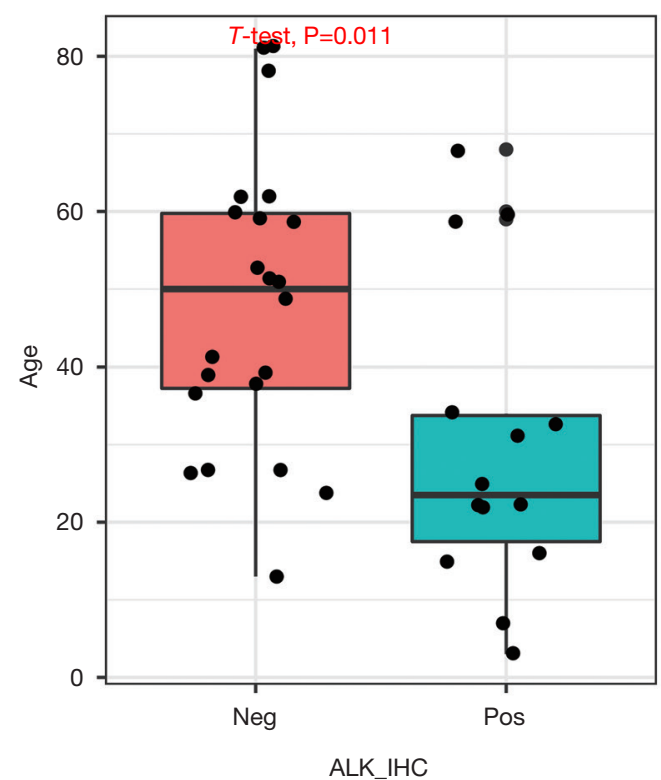

B $\quad P=0.03$

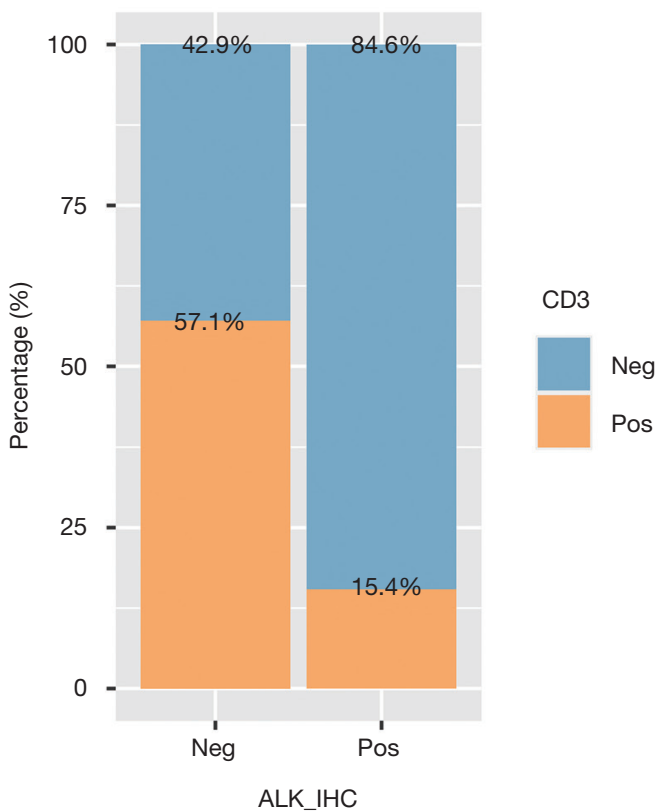

Figure 3 The correlations between anaplastic lymphoma kinase $(A L K)$ fusion status and clinical parameters. (A) Patients with immunohistochemistry (IHC)-based $A L K$ positive status were significantly younger as compared to $A L K$-negative patients. (B) Percentage of CD3-positive patients with different $A L K$ status. The threshold for immunohistochemistry immunopositivity of CD3 was $>20 \%$ of tumor cells.

characterized clinically, the genetic features of $A L K$ negative ALCLs are not well defined. Previous studies reported that the most commonly mutated genes in $A L K$ negative ALCL were $7 A K 1$, STAT3, PR/SET domain 1 (PRDM1), TP53, TET2, and FAS (22,23). The most common mutation among $A L K$-negative patients in our study was TP53 (27.3\%), followed by NOTCH1 (22.7\%), KMT2D (13.6\%), KRAS (13.6\%), TET2 (13.6\%), JAK1 (9.1\%), STAT3 (4.5\%), and FAS (4.5\%). However, PRDM1, which has been reported as a common mutation in $A L K$ negative ALCL patients, was not detected in our $A L K$ negative cohort, which indicates that Chinese systemic ALCL patients may have a unique somatic mutational profile. Recently, chromosomal rearrangements of the DUSP 22 and TP63 genes were reported in $A L K$-negative ALCL, with an incidence of $30 \%$ and $8 \%$, respectively $(10,24)$. In our study, however, DUSP22 rearrangement was detected in three patients, accounting for only $13.6 \%$ of the $A L K$-negative ALCL patients; this discrepancy can be partly attributed to the small sample size. Detection of TP63 rearrangement was not performed in our cohort.

In our study, start-loss of $B 2 M$ gene was detected in one
$A L K$-negative patient. This patient showed a favorable prognosis, with OS of 93 months and counting. Inactivating $B 2 M$ mutations, including exon-1 splice-donor, start codon mutations, out-of-frame first-exon deletions, and acceptorsite mutations, may induce the loss of expression of the major histocompatibility complex class I complex, which is vital for antigen presentation (25). Inactivating $B 2 M$ mutations have been detected in both Hodgkin and nonHodgkin lymphoma patients. A lack of B2M expression is associated with a favorable prognosis in Hodgkin lymphoma patients; in contrast, it is associated with unfavorable prognosis in non-Hodgkin lymphoma patients $(25,26)$. Low B2M $(\leq 3 \mathrm{mg} / \mathrm{dL})$ has also been reported to be a favorable prognostic factor in ALCL (27). To the best of our knowledge, our study provides the first evidence of start-loss of B2M in an ALCL patient, thus suggesting the prognostic value of $B 2 M$ in ALCL. This patient harbored DUSP22 rearrangement, which is a favorable prognostic biomarker of ALCL. Therefore, the prognostic value of $B 2 M$ mutation needs to be further explored.

This study has some limitations. First, this is a retrospective study, which has all the drawbacks associated 
with a retrospective study including missing clinical data. Second, this study has a relatively small sample size, and limited clinical and follow-up data, which may have impacted the analyses. Third, this study was conducted in a single center that could introduce sample or population bias. Nevertheless, our study revealed the unique genomic profiles of Chinese systemic ALCL patients and represents an incremental step in improving the understanding of genetic heterogeneity in ALCL.

\section{Acknowledgments}

We would like to thank Mr. Bing Li, Dr. Han Han-Zhang, Dr. Lu Zhang, Dr. Xuejing Li, Dr. Analyn Lizaso, Dr. Ting Bei and Mr. Chanhe Li of Burning Rock Biotech for their help in data analysis, manuscript editing, and valuable discussion.

Funding: This research was supported by the Science and Technology Program of Fujian Province, China (No. 2018Y2003, No. 2018-CX-10, No. 2019L3018, and No. 2019Y91010045).

\section{Footnote}

Reporting Checklist: The authors have completed the MDAR reporting checklist. Available at http://dx.doi.org/10.21037/ atm-20-7574

Data Sharing Statement: Available at http://dx.doi. org/10.21037/atm-20-7574

Conflicts of Interest: All authors have completed the ICMJE uniform disclosure form (available at http://dx.doi. org/10.21037/atm-20-7574). The authors have no conflicts of interest to declare.

Ethical Statement: The authors are accountable for all aspects of the work in ensuring that questions related to the accuracy or integrity of any part of the work are appropriately investigated and resolved. All procedures involving human participants were performed in accordance with the Declaration of Helsinki (as revised in 2013). The study protocol was approved by the Ethics Committee of Fujian Medical University Cancer Hospital and Fujian Cancer Hospital (approval number: 2017-055-01). Written informed consent was provided by all the patients included in the study.
Open Access Statement: This is an Open Access article distributed in accordance with the Creative Commons Attribution-NonCommercial-NoDerivs 4.0 International License (CC BY-NC-ND 4.0), which permits the noncommercial replication and distribution of the article with the strict proviso that no changes or edits are made and the original work is properly cited (including links to both the formal publication through the relevant DOI and the license). See: https://creativecommons.org/licenses/by-nc-nd/4.0/.

\section{References}

1. Montes-Mojarro IA, Steinhilber J, Bonzheim I, et al. The Pathological Spectrum of Systemic Anaplastic Large Cell Lymphoma (ALCL). Cancers (Basel) 2018;10:107.

2. Hapgood G, Savage KJ. The biology and management of systemic anaplastic large cell lymphoma. Blood 2015;126:17-25.

3. Eyre TA, Khan D, Hall GW, et al. Anaplastic lymphoma kinase-positive anaplastic large cell lymphoma: current and future perspectives in adult and paediatric disease. Eur J Haematol 2014;93:455-68.

4. Gascoyne RD, Aoun P, Wu D, et al. Prognostic significance of anaplastic lymphoma kinase (ALK) protein expression in adults with anaplastic large cell lymphoma. Blood 1999;93:3913-21.

5. Katayama R, Lovly CM, Shaw AT. Therapeutic targeting of anaplastic lymphoma kinase in lung cancer: a paradigm for precision cancer medicine. Clin Cancer Res 2015;21:2227-35.

6. Fisher RI, Gaynor ER, Dahlberg S, et al. Comparison of a standard regimen (CHOP) with three intensive chemotherapy regimens for advanced non-Hodgkin's lymphoma. N Engl J Med 1993;328:1002-6.

7. Savage KJ, Harris NL, Vose JM, et al. ALKanaplastic large-cell lymphoma is clinically and immunophenotypically different from both ALK+ ALCL and peripheral T-cell lymphoma, not otherwise specified: report from the International Peripheral T-Cell Lymphoma Project. Blood 2008;111:5496-504.

8. d'Amore F, Relander T, Lauritzsen GF, et al. Up-front autologous stem-cell transplantation in peripheral T-cell lymphoma: NLG-T-01. J Clin Oncol 2012;30:3093-9.

9. Onaindia A, de Villambrosia SG, Prieto-Torres L, et al. DUSP22-rearranged anaplastic lymphomas are characterized by specific morphological features and a lack of cytotoxic and JAK/STAT surrogate markers. 
Haematologica 2019;104:e158-62.

10. Parrilla Castellar ER, Jaffe ES, Said JW, et al. ALKnegative anaplastic large cell lymphoma is a genetically heterogeneous disease with widely disparate clinical outcomes. Blood 2014;124:1473-80.

11. Pedersen MB, Hamilton-Dutoit SJ, Bendix K, et al. DUSP22 and TP63 rearrangements predict outcome of ALK-negative anaplastic large cell lymphoma: a Danish cohort study. Blood 2017;130:554-7.

12. Hapgood G, Ben-Neriah S, Mottok A, et al. Identification of high-risk DUSP22-rearranged ALK-negative anaplastic large cell lymphoma. Br J Haematol 2019;186:e28-e31.

13. NCCN Clinical Practice Guidelines in Oncology for T-cell lymphomas. Version 3. 2020 [database on the Internet]. National Comprehensive Cancer Network (NCCN). 2020. Available online: https://www.nccn.org/. Accessed: June 15, 2020.

14. Younes A, Hilden P, Coiffier B, et al. International Working Group consensus response evaluation criteria in lymphoma (RECIL 2017). Annals of Oncology 2017;28:1436-47.

15. Li H, Durbin R. Fast and accurate short read alignment with Burrows-Wheeler transform. Bioinformatics 2009;25:1754-60.

16. McKenna A, Hanna M, Banks E, et al. The Genome Analysis Toolkit: a MapReduce framework for analyzing next-generation DNA sequencing data. Genome Res 2010;20:1297-303.

17. Koboldt DC, Zhang Q, Larson DE, et al. VarScan 2: somatic mutation and copy number alteration discovery in cancer by exome sequencing. Genome Res 2012;22:568-76.

18. Wang K, Li M, Hakonarson H. ANNOVAR: functional annotation of genetic variants from high-throughput sequencing data. Nucleic Acids Res 2010;38:e164.

Cite this article as: Zhong $\mathrm{LH}, \mathrm{Wu} \mathrm{ZD}$, Wang JC, Wu ZZ, Chen FF, Zhu WF, Chen YP, Chen G. Molecular profiling of Chinese systemic anaplastic large cell lymphoma patients: novel evidence of genetic heterogeneity. Ann Transl Med 2021;9(2):128. doi: 10.21037/atm-20-7574
19. Cingolani P, Platts A, Wang le L, et al. A program for annotating and predicting the effects of single nucleotide polymorphisms, SnpEff: SNPs in the genome of Drosophila melanogaster strain w1118; iso-2; iso-3. Fly (Austin) 2012;6:80-92.

20. Newman AM, Bratman SV, Stehr H, et al. FACTERA: a practical method for the discovery of genomic rearrangements at breakpoint resolution. Bioinformatics 2014;30:3390-3.

21. Morris SW, Kirstein MN, Valentine MB, et al. Sequence Correction. Science 1995;267:316-7.

22. Crescenzo R, Abate F, Lasorsa E, et al. Convergent mutations and kinase fusions lead to oncogenic STAT3 activation in anaplastic large cell lymphoma. Cancer Cell 2015;27:516-32.

23. Mereu E, Pellegrino E, Scarfo I, et al. The heterogeneous landscape of ALK negative ALCL. Oncotarget 2017;8:18525-36.

24. Feldman AL, Dogan A, Smith DI, et al. Discovery of recurrent $\mathrm{t}(6 ; 7)(\mathrm{p} 25.3 ; \mathrm{q} 32.3)$ translocations in ALKnegative anaplastic large cell lymphomas by massively parallel genomic sequencing. Blood 2011;117:915-9.

25. Reichel J, Chadburn A, Rubinstein PG, et al. Flow sorting and exome sequencing reveal the oncogenome of primary Hodgkin and Reed-Sternberg cells. Blood 2015;125:1061-72.

26. Amiot L, Onno M, Lamy T, et al. Loss of HLA molecules in B lymphomas is associated with an aggressive clinical course. Br J Haematol 1998;100:655-63.

27. Sibon D, Fournier M, Briere J, et al. Long-term outcome of adults with systemic anaplastic large-cell lymphoma treated within the Groupe d'Etude des Lymphomes de l'Adulte trials. J Clin Oncol 2012;30:3939-46.

(English Language Editor: J. Reynolds) 